\title{
Akılcı İlaç Kullanımının Boylamsal Bir Koridor Şeklinde Üç Yıllık Klinik Eğitim Programına Entegrasyonu
}

\section{Integration of Rational Pharmacotherapy to a Three-Year Clinical Training Program as a Longitudinal Threads}

\author{
Berna Terzioğlu Bebitoğlul (ORCID ID: 0000-0003-4601-7871) \\ Mehmet Ali Gülpınar (ORCID ID: 0000-0003-1765-3529) \\ ${ }^{1}$ İstanbul Medeniyet Üniversitesi Tıp Fakültesi, Tıbbi Farmakoloji Anabilim Dalı \\ ${ }^{2}$ Marmara Üniversitesi, Tıp Fakültesi, Tıp Eğitimi Anabilim Dalı \\ Yazışma Adresi: \\ Berna Terzioğlu Bebitoğlu \\ İstanbul Medeniyet Üniversitesi Tıp Fakültesi, Tıbbi Farmakoloji Anabilim Dalı, \\ Kuzey Yerleşkesi, Ünalan Mah. D-100 Karayolu Ünalan, Üsküdar, İSTANBUL \\ Telefon: 05324114979 e-posta: bernaterzioglu@gmail.com
}

Anahtar Sözcükler:

Akılcı ilaç kullanımı, tıp eğitimi, klinik farmakoloji, entegrasyon

Keywords:

Rational pharmacotherapy, medical education, clinical pharmacology, integration

Gönderilme Tarihi Submitted:30.05.2019 Kabul Tarihi

Accepted: 03.10.2019

\section{ÖZET:}

Akılcı ilaç kullanımı ile ilgili ülkemizde ve dünyada çok sayıda eğitim faaliyeti yürütülmektedir. Ancak yapılan çalışmalarda günümüzde halen akılcı olmayan ilaç kullanımı olduğu, hekimlerin ve özellikle yeni mezun hekimlerin bu konuda yeterliğe sahip olmadığı ve öğrencilerin kendilerini reçete yazma konusunda yeterli hissetmedikleri bildirilmektedir. $\mathrm{Bu}$ nedenle mezuniyet öncesi eğitim döneminde başlayan ve ileri eğitim ve meslek yaşamları boyunca devam eden eğitimlerle akılcı ilaç kullanımının devamlılığının sürdürülmesi önemlidir.

Öğrenen merkezli eğitim modellerinde öğrenenlerin kendi öğrenme süreçlerini yönettiği probleme dayalı öğrenme ve işbaşında öğrenme gibi aktif öğrenme yöntemleriyle rasyonel farmakoterapi eğitiminin yürütülmesi, öğrenmede kalıcılığın artırılması ve doktorların ilerideki klinik pratiklerinde kendi başlarına kaldıklarında rasyonel ilaç kullanımını değişen koşullara göre uygulayabilme yeterliğini kazanmaları için gereklidir.

Klinik tedavi kılavuzları ve temel ilaç listeleri ile uyumlu rasyonel farmakoterapi eğitimi iyi reçeteleme alışkanlığı kazandırmak için yararlı olmaktadır. Öğrencilerin bilgi, beceri ve tutumları dikkate alarak, sıklıkla karşılaşılan klinik durumlar üzerinden yapılan probleme dayalı öğrenme ile işbaşında öğrenme etkinlikleri rasyonel ilaç kullanımı kazandırılması noktasında tercih edilebilecek

Künye: Terzioğlu Bebitoğlu B, Gülpınar MA. Akılcı İlaç Kullanımının Boylamsal Bir Koridor Şeklinde Üç Yıllık Klinik Eğitim Programına Entegrasyonu. Tıp Eğitimi Dünyası. 2019;18(56):110-122 
etkili yöntemlerin başında gelmektedir. Yine, toplumda sık görülen hastalıklara yönelik rasyonel farmakoterapi eğitim modülleri ile, akılcı ilaç kullanımının tıp fakültelerinde klinik eğitim dönemlerinde tüm staj programlarına boylamsal bir koridor olarak entegre bir şekilde dahil edilmesi ile, öğrencilerin karşılaşacakları hastalıklarda reçete yazmada kendilerine güven duymalarına, kişisel ilaç formülerlerini hazırlayabilmelerine ve güvenli ve etkili tedavi planları oluşturabilmelerine olanak sağlayacaktır.

\section{ABSTRACT:}

Several educational activities are carried out in our country and in the world regarding rational pharmacotherapy. However, it is reported that there is still irrational drug use, physicians and especially new graduates do not have the prescribing competency and medical students do not feel sufficient to prescribe themselves. For this reason, maintaining the continuity of rational drug use with the trainings started in the undergraduate period and continued in the period of professional life training is important. It is necessary to conduct the rational pharmacotherapy training with active learning methods such as problem based learning and workplace learning models in which the learner manage their own learning process, long term retention of knowledge increase the competence of the physicians to apply the rational drug usage according to the changing conditions in their future clinical practices consolidate.

Rational pharmacotherapy training, which is compatible with clinical treatment guidelines and basic drug lists, is useful for gaining good prescribing habits. Considering the knowledge, skills and attitudes of the students, problembased learning together with workplace learning activities on frequently encountered clinical conditions are the leading methods that can be preferred to bring rational drug use. Also, the rational pharmacotherapy training modules for the common diseases in the community will be included in every clerkship program as longitudinal threads in the medical faculties and will allow students to feel confident in the prescription writing, to prepare their personal drug formulas and to provide safe and effective treatment plan.

\section{GíRiş}

Bu yazıda Akılcı İlaç Kullanımı (AİK) kavramı ile ilgili dünyada ve ülkemizdeki durum ve AİK'nın uygulanmasında tıp eğitiminin yeri sunulmaya çalışılmıştır. Akılcı ilaç kullanımında, sadece sağlık çalışanları değil hastalar, toplumdaki her bir birey, ilaç üreticileri, sağlık otoritesi, sosyal güvenlik kurumu gibi tüm taraflara roller düşmektedir. Söz konusu taraflar arasında, akılcı ilaç kullanımı ile ilgili strateji geliştirme ve uygulanmasında işbirliğine ihtiyaç vardır. İlacın tedavide kullanımına karar veren hekim ile başlayan süreçte bu konunun tıp eğitimindeki yeri kuşkusuz en önemli unsurlardan birisidir.

Dünya Sağlık Örgütü (DSÖ) tarafindan 1985 yılında sunulan akılcı ilaç kullanımı (rasyonel ilaç kullanımı) kavramı şu şekilde tanımlanmıştır: Bir hastanın ilacını klinik ihtiyacına uygun olarak, kendi bireysel gereksinimini karşılayan dozda, yeterli uygun sürede ve kendine ve topluma mümkün olan en düşük maliyette kullanıyor olması (1). Akılcı ilaç kullanımı ucuz ilaç ya da indirimli ilaç kullanımı anlamına gelmediği gibi tümüyle standardize edilmiş hastalıkların aynı biçimde tedavi edilmesi gerektiği anlamına da gelmemektedir.

\section{İlaçların Akılcı Kullanımına İlişkin Mevcut Durum ve Sonuçları}

Herhangi bir endikasyon için uygun ilaç, ancak etkililik, güvenlik, uygunluk ve maliyet 
kriterleri dikkate alındığında akılcı olarak seçilmiş olur. İlaçların rasyonel olmayan kullanımı bu unsurlar dikkate alınmadığında ortaya çıkmaktadır. Dünya genelinde reçete edilen ilaçların \% 50'sinden fazlası yanlış kullanılmakta veya uygunsuz satılmakta iken hastaların \% 50'si ilaçlarını doğru olarak kullanmamaktadır. Dünya nüfusunun yaklaşık üçte biri gerekli olan ilaca ulaşamamaktadır $(1,2)$. Sik karşılaşılan rasyonel olmayan ilaç kullanımı durumları ise şunlardır: Bir hastada çok fazla sayıda ilaç kullanımı (polifarmasi); ilaç-ilaç etkileşimi ve besin-ilaç etkileşimlerinin gözardı edilmesi; ilaçların gerekli olmadığı halde aşırı kullanımı, klinik rehberlere uyumsuz tedavi seçimi, bilinçsiz gıda takviyesi ve bitkisel ürünlerin kullanımı, antimikrobiyallerin uygunsuz kullanımı, sıklıkla uygun olmayan dozda, bakteriyel olmayan enfeksiyonlarda kullanımı; oral formulasyon daha uygun olduğu halde enjeksiyonların aşırı kullanımı; klinik kılavuzlarla uyumlu reçeteleme yapılmaması; reçete ile alınması gereken ilaçların kendikendine kullanılması, uygunsuz kişisel tedavilere başvurulması $(3,4)$.

Akılcı olmayan ilaç kullanımı sonucu hastanın tedaviye uyumunun azalması, ilaç-ilaç etkileşimleri, ilaçlara karşı direnç gelişimi, hastalıkların tekrarlaması veya süresinin uzaması, tedavi maliyetlerinin artması ve advers olay görülme sıklığının artması gibi durumlar görülür. İlaçlara ulaşamamak ve uygun olmayan dozda kullanım özellikle çocukluk çağı enfeksiyonları ile hipertansiyon, diyabet, epilepsi ve mental bozukluklar gibi kronik hastalıklarda ciddi morbidite ve mortalite ile sonuçlanır. Uygunsuz veya aşırı ilaç kullanımı, kaynakların harcanmasına, hastaların kendilerinin fazla ödeme yapmasına, sonuç olarak hastaya zarar verme ve advers ilaç reaksiyonu gelişmesi gibi olumsuz sonuçlara neden olur. Yine antimikrobiyallerin aşırı kullanımı ile antimikrobiyal direnç gelişiminde artış, steril olmayan enjeksiyonlarla hepatit, HIV/AIDS veya kan ile bulaşan hastalıkların bulaşmasında artış gözlenir. Bu durum hastaların uygun olmayan ilaç talep etmelerine, stokların hızlı tükenmesi ile ilaçlara erişimin azalmasına, hastaların sağlık sistemine olan güvenlerinde kayba ve ülke ekonomisinde maddi yüke neden olur $(1,2,3,4)$.

Akılcı olmayan ilaç kullanımı sağlık sistemindeki tüm taraflara sorumluluk yüklemektedir. Sadece sağlık çalışanları değil hastalar, toplumdaki her bir birey, ilaç firmaları, sağlık otoritesi, sosyal güvenlik kurumu gibi tüm taraflar bu konu ile ilgili strateji geliştirme ve bunu uygulamada rolleri vardır. Bu nedenle öncelikle akılcı olmayan ilaç kullanımının nedenlerini belirleyerek çözüm stratejileri geliştirmek gerekir. Belirlenen problemlere yönelik stratejiler geliştirilmesi, reçete, ilaç dağıtımı ve takibi gibi gözlemlerin düzenli aralıklarla yapılarak durumun kontrol edilebilmesi ve eğitimlerin düzenlenmesi ile problemin çözülmesi sağlanabilir.

Rasyonel olmayan ilaç kullanımının nedenleri arasında konuya ilişkin bilgi ve beceri eksikliği, yeterli, doğru ve güncel bilgiye/kanıta dayanmayan sağlık uygulamaları, ilaçlara erişimde sınır olmaması, sağlık personelinin aşırı iş yükü, alışkanlıklar ile ilaç üreticilerinin promosyonları ve kârlılık teşvikleri yer almaktadır $(3,4)$.

İlaç Endüstrisi İşverenler Sendikası (IEİS) verilerine göre 2016 yılsonu satış verilerine göre dünya ilaç pazarının büyüklüğü 1,1 trilyon dolardır ve pazarın büyüklüğü noktasında Türkiye 16. sırada yer almaktadır (5). Bu verilere göre, 2016 yılında toplam ilaç pazarının \% 11,7'sini onkoloji ilaçları oluşturmaktadır. Bunu ikinci sırada anti-diabetik ilaçlar ve üçüncü 
sırada romatizma ilaçları takip etmektedir. Üstelik ilaç harcamaları ve ARGE yatırımlarının her yıl giderek arttığı bildirilmektedir. Tedavi alanlarına göre ilaç sıralamasının 2018 yılı için de benzer olduğu bildirilmiştir. 2018 yılında dünya genelinde ilaç harcamaları 1 trilyon 200 milyar dolar olup 2019 yılında yaklaşık yüzde 5 artış beklenmektedir (6). İlaç tüketimini ve artan büyüme payı düşünüldüğünde ilacın akılcı kullanımı daha da önem kazanmaktadır. Ülkemizde AİK'nın yaygınlaştırılması kapsamında yapılan çalışmalarda Reçete Bilgi Sistemi aracılığıyla hekimlerin yazdığı reçetelere ait veriler analiz edilmiştir. $\mathrm{Bu}$ analizlerde 2011-2012 y1lında Aile Hekimlerinin yazdığı reçetelerde antibiyotik bulunan reçete yüzdesi 2011 yilında \% 34,94 ve 2012 y1lında \% 33,99 olarak belirlenmiştir (7). $\mathrm{Bu}$ oranın Gaziantep ilinde sirasiyla \% 57,58 ve $\% 55,49$ olarak belirlenmesi üzerine, 2013 ve 2014 yıllarında Gaziantep ilinde İ1 Halk Sağlığı Müdürlüğü ve İl Sağlık Müdürlüğü işbirliği ile eğitim toplantıları düzenlemiştir. $\mathrm{Bu}$ toplantılarda serbest eczacilar, aile hekimleri ve hastanelerdeki enfeksiyon kontrol komitelerinde görevli sağlık çalışanları ile bir araya gelinerek, antibiyotik reçeteleme durumu hakkında bilgilendirmeler yapılarak, eczacılara ve tüm hekimlere yönelik eğitimler düzenlenmiştir. Daha sonra reçete bilgi sistemi aracılığıyla aile hekimlerinin Ekim 2013 - Haziran 2014 tarihleri arasındaki aylık reçete verileri bir önceki yılın aynı ayları ile karşılaştırılmış ve antibiyotik bulunan reçetelerde aylık \% 6,40-13,09 oranında azalmanın olduğu, aile hekimlerinin reçetelerinde antibiyotiklerin tercih edilmesinde aylik olarak \% 9,86-20,15 azalma olduğu belirlenmiştir (7). Refik Saydam Hıfzıssıhha Merkezi Başkanlığı Hıfzıssıhha Mektebi Müdürlüğü tarafından 2009 yılında yürütülen bir araştırmada ise ülkemizde 10 ildeki sağlık kuruluşlarındaki hekimlerin yazdıkları reçetelerin içeriği, AİK ilkeleri göz önünde tutularak incelenmiştir. Antibiyotiklerin, reçetelere yazılmış tüm ilaçların \% 15,49'unu oluşturduğu, analjeziklerin reçetelere yazılmış tüm ilaçların \% 19,56'sını ve enjeksiyon preparatlarının ise reçetelere yazılmış tüm ilaçların \% 4,38'ini oluşturduğu belirlenmiştir. Reçete içeriklerinin AİK açısından çeşitlilik gösterdiği, incelenen endikasyonlar arasında önemli farklılıkların olduğu ve AİK'in yaygınlaştırılmasına yönelik iyileştirme faaliyetlerine ihtiyaç olduğu bildirilmiştir (8).

\section{Dünyada Akılcı İlaç Kullanımına Yönelik Eğitim Faaliyetleri}

Rasyonel ilaç kullanımını toplumlara yaymak için ülkeler çeşitli stratejiler geliştirmekte, ilaç kullanımını takibe almakta ve düzenledikleri eğitimlerle bu kavramı vurgulamaktadırlar. Dünya Sağlık Örgütü'nün bu konuda yaptığ1 faaliyetlerin başında ülkelerle işbirliği içinde eğitimler düzenlemektir. Bunlardan ilk sırada yer alanlar şunlardır (4):

- Rasyonel İlaç Kullanımı Uluslararası Ağı ile işbirliği içinde ABD Sağlık Yönetim Bilimleri tarafından koordine edilen ilaçların rasyonel kullanımını teşvik etme eğitimi ve birinci basamak sağlık bakımında ilaç kullanımı ve ilacı sağlayanların rasyonel ilaç kullanımı eğitimi,

- Amsterdam Üniversitesi ile işbirliği içinde tüketicilerin akılcı ilaç kullanımı eğitimi,

- ABD Sağlık Yönetim Bilimleri tarafindan koordine edilen hastaneler ve bölgelerde rasyonel ilaç kullanımı eğitimleri,

- Groningen Üniversitesi ile işbirliği içinde Probleme dayalı farmakoterapi eğitimi ile DSÖ İyi Reçete Yazma Kılavuzuna göre probleme dayalı rasyonel reçeteleme yaklaşımı eğitimi $(1,2,3,4)$.

Ayrıca, Newcastle Üniversitesi ile birlikte 
farmakoekonomi eğitiminde ilaç seçiminde ekonomik değerlendirme eğitimi yapılmıştır. Boston Üniversitesi ile birlikte gelişmekte olan ülkeler için ilaç politikaları eğitiminde daha rasyonel ilaç kullanımı teşviki ile ilgili genel ilaç politikaları ele alınmaktadır. İlaç tüketimini ölçmek için Anatomik Terapötik Sınıflandırma (ATC)/Belirlenen Günlük Doz (DDD) ATC/ DDD metodunun anlatıldığı eğitim DSÖ İlaç İstatistikleri Metodu İşbirliği merkezi ile birlikte yürütülmektedir (4).

\section{Türkiye’de Akılcı İlaç Kullanımına Yönelik Eğitim Faaliyetleri}

Ülkemizde AİK'nın teşvik edilmesi için yapılan düzeltici faaliyetler 2014-2017 Ulusal Eylem Planında yayınlanmıştır. Bu planda hekimlerin AİK konusunda farkındalığının artırılması, AİK ilkelerine uygun reçete yazma davranışlarının oluşturulmasında pozitif performansla teşvik edilmeleri, mezuniyet sonrası eğitimlerinde devamlılığın sağlanması, AİK ile ilgili araştırmalarının teşviki, tüm Tıp ve Diş Hekimliği Fakültelerinde AİK ile ilgili ders veya staj programının yer alması, fakültelerde yapılan stajyerlik ve intörnlük çalışmalarında AİK ile ilgili araştırmaların yer alması, uzmanlık bitirme tezlerinde AİK ile ilgili araştırmaların yer alması, tüm asistan hekimlerin AİK ile ilgili eğitimi almış olmaları gibi özellikle eğitim faaliyetleri vurgulanmıştır (9).

\section{Akılcı İlaç Kullanımı ve Mezuniyet Öncesi Tıp Eğitimi}

Akılcı İlaç Kullanımında tüm taraflara yönelik eğitimler önemli olmakla birlikte özellikle doktorların mezuniyet öncesi eğitim döneminde başlayan ve mezuniyet sonrası eğitim ve sürekli mesleki gelişim boyunca devam eden eğitimlerinin akılcı ilaç kullanımının devamlılığının sürdürülmesinde rolü büyüktür
(10).

Öğrenen merkezli eğitim modellerinde öğrenenlerin kendi öğrenme süreçlerini kendilerinin yönettiği öğrenme yöntemleri ile rasyonel farmakoterapi eğitimlerinin yürütülmesi, öğrenmede kalıcılığının artması, doktorların ilerideki klinik pratiklerinde kendi başlarına kaldıklarında rasyonel ilaç kullanımını değişen koşullara göre uygulayabilme yeterliğini kazanmaları için gereklidir. Özellikle mezuniyet öncesi eğitim programlarında öğrencilere farmakoterapi ile ilgili temel kavramların aktarılması, öğrencilerin klinik pratikte uygulama örneklerini deneyimlemesi ve öğrencilere rasyonel farmakoterapi prensiplerine göre reçeteleme alışkanlığı kazandırılması gelecekteki reçeteleme aktivitelerini belirlemesi açısından çok önemli bir dönemdir $(10,11)$.

\section{Tercih edilen öğrenme ve değerlendirme yöntemleri}

Probleme dayalı öğrenme ile farmakoterapi eğitiminin yapılması uzun yıllardan beri hem dünyada hem de ülkemizde birçok tıp fakültesinde eğitim programları içinde yer almakta; değerlendirme sürecinde ise Nesnel Yapılandırılmış Klinik Sınav sıklıkla kullanılmaktadır (12,13). Klinik tedavi kılavuzları ve temel ilaç listeleri ile uyumlu rasyonel farmakoterapi eğitimi iyi reçeteleme alışkanlığı kazandırmak için yararlı olmaktadır. Öğrencilerin bilgi, beceri ve tutumunu dikkate alarak, sıklıkla karşılaşılan klinik durumlar üzerinden yapılan probleme dayalı öğrenme oturumları rasyonel ilaç kullanımı kazandırılması açısından başarılı olmaktadır (12).

Etkileşimli öğrenme yöntemleri açısından tercih edilebilecek diğer öğrenme yöntemleri arasında Takım Çalışmasına Dayalı Öğrenme (TeamBased Learning) ve Olguya Dayalı Birlikte 
Öğrenme (Case-Based Collaborative Learning Learning) yöntemleri bulunmaktadır. Öğrenme süreçleri farklı olmakla birlikte bu üç öğrenme yönteminin esasını küçük gruplarla (4-10) birlikte gerçekleştirilen olgu çözümlemeleri oluşturmaktadır $(14,15)$.

Ülkemizde ilk olarak Marmara Üniversitesi Tıp Fakültesi'nde 1996 yılında Dünya Sağlık Örgütü (DSÖ) ve Groningen Üniversitesi tarafından geliştirilen eğitim modeli kullanılarak probleme dayalı Akılcı ilaç kullanımı eğitimi pilot uygulaması başlatıldı. Öğrencilerden olumlu geribildirimler alınması üzerine program geliştirildi ve tıp fakültesi eğitim programında klinik eğitim dönemine 2 haftalık bir program olarak eklendi $(13,16)$. $\mathrm{Bu}$ program çerçevesinde DSÖ Reçete Yazma Kılavuzu çeşitli tıp fakültelerinde adapte edilmiş ve kullanılmaktadır (13). Bu programda basamaklar halinde, önce hastanın problemini tanımlanır, tedavi amaçları belirlenir, kişisel ilaç (K-ilaç) seçilir ve K-ilacın uygunluğu değerlendirilerek etkinliği ve güvenliği kontrol edilir, tedaviye başlanır, hastaya bilgilendirme yapılır (hasta için gerekli bilgiler, talimatlar ve uyanlar anlatılır) ve tedavi izlenir ya da sonlandirilir (13).

Akılcı tedavi sürecindeki tedaviyi düzenleme ve reçete yazma basamağı şüphesiz en önemli ve tedaviyi belirleyici unsurdur. $\mathrm{Bu}$ süreçte doktordan tanı sonrasında, tedavi ile ilgili güncel/kanıta dayalı bilginin yanısıra ilacın etkililiği, güvenliliği, uygunluğu ve maliyeti dikkate alınarak en uygun tedaviyi düzenlemesi; yeterli doz, uygun uygulama yolu, yeterli tedavi süresi ile birlikte reçeteyi yazması ve hastaya reçetede yazanlar ile ilgili bilgilendirme yapması beklenir. $\mathrm{Bu}$ noktada hekimlerin bu basamaklarla ilgili bilgileri ve farkındalıklarının yüksek olması çok önemlidir. Ancak bu durumda doktor hastayı doğru sürede ve doğru şekilde tedavi edecek, hastanın tedaviye uyumunu artıracak ve tedavinin tamamlanmasına katk1 sağlayacaktır (13).

\section{Reçete yazma}

Reçete yazma sağlık bakım sürecinin önemli bir parçasıdır. Reçete yazımında, seçilen ilaç, hastaya doğru formatta yazılmalıdır ve her ne kadar günümüzde artık elektronik reçete kullanılır olsa da, kağıda elle yazılan reçete pratiğinin unutulmaması gerekir. İlaçlar hastanın iyiliği için gerekli olsa da yanlış yazılan reçete zararlı etkilere neden olabilmektedir. Reçeteleme hatalarının yarısının potansiyel olarak önlenebilir olduğu ve reçete eden hekimlerin sınırlı farmakoloji ve farmakoterapi bilgisinden kaynaklandığ 1 belirlenmiştir. $\mathrm{Bu}$ nedenle bu hataların yapılmasını önlemek için tıp eğitimi sırasında verilen farmakoloji eğitiminin rolü büyüktür $(17,18,19)$.

Hastanelerde yapılan reçeteleme hatalarının çoğunluğunun tıp fakültesinden yeni mezun olan genç hekimler tarafindan yapıldığı ve bunda bireysel, çevresel ve idari düzeyde birçok faktörün etkisi olduğu öne sürülmektedir. Yeni mezun hekimlerin bu konudaki bilgi ve becerisi artırılarak olası hatalar azaltılması mümkün olabileceğinden tıp eğitiminde bu konuya daha fazla yer verilmesi gerekmektedir (20,21). İngiltere'de yapılan çalışmalarda tıbbi hataların en sık nedenlerinden birisi reçeteleme hataları olduğu belirlenmiş olup reçete hatalarının \%43'ünün yanlış ve ihlal, \%57'sinin ise ihmalden kaynaklandığı bildirilmiştir (17).

İngiltere'ye hastane başvurularının yaklaşık olarak \%1-2'sinin ilaç hatalarına bağlı olduğu, bunların da çoğunun reçetelerdeki hatalardan kaynaklandığı belirlenmiştir. Yapılan başka bir çalışmada yatan hasta reçeteleri incelenmiş ve ciddi hatalar olduğu ve bunların çoğunun ilaç dozu seçiminden kaynaklandığı bildirilmiştir 
$(21,22,23,24,25)$.

Reçete yazma yeni hekimlerin en sık yaptığ görevlerden olup kanıta dayalı bilginin yanısıra karar verme ve değerlendirme gibi yeterlikleri gerektiren kompleks bir iştir (26). Tip fakültesi öğrencileri ve yeni mezun genç hekimlerin reçete yazmada zorlandıkları saptanmıştır (27). Reçete yazma becerisi deneyimle birlikte temel klinik farmakoloji bilgisi ve ilaçlar hakkında yeterli bilgiyi gerektirmektedir $(20,21)$. Bu durum yeni mezun hekimler için zor bir süreç olup birçok ilaç arasında seçim yapmayı gerektirmesi, tedavi rejimlerinin karmaşık olması, yeni ilaçların piyasaya çıkması ile birlikte yaratılan kafa karışıklığı gibi birçok faktör nedeniyle hekimler için bu süreci daha da zorlaştırmaktadır $(26,27)$.

İngiltere'de, 25 tıp fakültesinden 2413 öğrencinin katılımıyla yapılan bir çalışmada, çalışmaya katılanların sadece \% $38^{\prime}$ inin kendisini reçete yazma konusunda yeterli hissettiği, \% 35'inin eğitimleri süresince üç defadan fazla hasta tabelası doldurduğu ve \% 29'unun reçete yazma becerisini kazandığını düşündüğü belirlenmiştir (28).

Reçete yazma becerisinin araştırıldığ 1 makalelerin incelendiği bir çalışmada, son sınıf öğrencilerinin reçete yazma yeterlilikleri değerlendirilmiş ve yapılan çalışmaların sonuçlarına göre son sınıf öğrencilerin güvenli ve etkili reçete yazma yeterliklerinin yeterli düzeyde olmadığı görülmüş ve farmakoloji eğitiminde yapılacak değişikliklerle eğitimde reçete yazmaya önem verilmesi gerektiği vurgulanmıştır (29).

Valide edilmiş tek farmakoloji ve farmakoterapi eğitim aracı DSÖ'nün doğru reçete yazma kılavuzunda tanımladığı 6-basamaklı metodudur. $\mathrm{Bu}$ metodun özellikle reçete yazanın düşünme sürecini geliştirmeye yönelik öğrenenler için faydalı olduğu gösterilmiştir $(11,12,30)$. DSÖ nün önerdiği reçete kılavuzuna yönelik hazırlanmış online "National Prescribing Curriculum (NPC)" reçete yazma modülü, sağlı alanındaki öğrencilerin almaları istenmiş ve bu modülle öğrencilerin temel ve klinik farmakoloji bilgilerinde artış olduğu bildirilmiştir (31). Ülkemizde rasyonel farmakoterapi eğitiminin tıp eğitiminde uygulandığ1 okullarda yapılan çalışmalarda da bu eğitimlerle reçete yazma alışkanlı̆̆ının geliştiği ve etkinin uzun süreli olduğu gösterilmiştir (16,32). Ülkemizde 2011 yılında yapılan bir çalışmaya göre tıp fakültelerinin $\%$ 70,3'ünde AİK eğitimleri verilmektedir (33). Farmakoloji anabilim dalları tarafindan yürütülen bu eğitimler çoğunlukla dördüncü veya beşinci sınıflarda uygulanmaktadır (33). $\mathrm{Bu}$ eğitimler klinik eğitim programlarında, çoğunlukla diğer stajlardan bağımsız olarak 20-29 saat süreli ayrı stajlar şeklinde yer almaktadır. Gerek diğer stajlardan ayrı olarak kurgulanan bu yapısı gerekse yeterli olmayan süresi ve kapsamı nedeniyle bu eğitimlerden elde edinilen sonuçlar hedeflenen düzeyinin altında kalmaktadır (33).

Tip eğitimi süresince reçete yazmada yetersiz eğitim alınmış olması önemli olup reçete hatalarının sebebi olduğu gösterilmiş ve yeterli eğitim ile reçete yazma performanslarında iyileşme olduğu belirlenmiştir. $\mathrm{Bu}$ nedenle tıp eğitimi sürecinde tutum ve davranışların kazandırılması ve beş-altı yıla yayılmış eğitimler, uzun süreli tutum ve becerinin gelişmesini sağlayabilir $(34,35,36)$.

Klinik Eğitimde Akılcı İlaç Kullanımı Eğitimi İçin Yeni Bir Yaklaşım: Boylamsal koridorla AİK eğitiminin staj programlarma entegre edilmesi 
Akılcı ilaç kullanıma ilişkin hedeflenen yeterliklerin öğrenciler kazanılabilmesi ve reçete hatalarının önlenebilmesi, tıp eğitimi sırasında verilen farmakoloji eğitiminin geliştirilmesi ile mümkündür. Bu noktada özellikle klinik eğitim döneminde, hali hazırda uygulanmakta olan 1-2 haftalık staj programlarının tek başlarına hedeflenen kazanımlar için yeterli olmayacağı görülmelidir. Yeni bir yaklaşım benimsenerek AIIK'na ilişkin yeterlikler ve AİK eğitimleri tüm stajlar boyunca devam edecek koridorlardan birisi olarak belirlenmeli (Şekil 1) ve seçilmiş olgular/hastalıklar üzerinden 4., 5. ve 6. Sinıf staj programlarının içine (Şekil 2), modüller şekilde yedirilmeli, entegre edilmelidir (37). Öğrenme ve değerlendirme yöntemi olarak bu modüllerde daha çok probleme dayalı öğrenme, takım çalışmasına dayalı öğrenme, olguya dayalı birlikte öğrenme gibi etkileşimli öğrenme yöntemleri ve Nesnel Yapılandırılmış Klinik Sınav gibi standardize değerlendirme yöntemleri ile klinikte/iş başında öğrenme ve değerlendirme yöntemleri (Olguya Dayalı Tartışma, Mini Klinik Sınav, akılcı ilaç kullanıma odaklı yapılandırılmış hasta viziti veya seçilmiş hasta dosyaları üzerinden yapılacak küçük grup oturumları vb.) tercih edilmelidir $(14,15)$.

Modüllerde olguya dayalı etkileşimli öğrenme oturumlarının tercih edilmesi önemlidir ve yapılan çalışmalar bu yönde bulgular sunmaktadır. Örneğin bir çalışmada, küçük gruplarda probleme dayalı ögrenme modeli ile büyük gruplarda yapılan reçete yazma eğitimi karşılaştırılmış ve öğrencilerin \%95,3'ünün küçük gruplarda öğrenmenin klinik farmakoloji bilgisini kullanmada ve reçete yazmada daha iyi öğrendiklerini bildirdikleri belirtilmiştir (38).

Lübnan'da yapılan ve 6-7 kişilik gruplarla takım çalışmasına dayalı öğrenme modelinin kullanıldığ 1 bir çalışmada ise 2008 yılından itibaren ayda-iki defa, 4. yıldaki 3 aylık iç hastalıkları rotasyonu sirasinda 90 dakikalık 6 oturumda "rasyonel reçete yazma" eğitimleri gerçekleştirilmiştir. Öğrenciler oturumlarda DSÖ kriterlerine uygun reçete yazma ve kişisel formüller oluşturma firsatı bulduklarını belirtmişlerdir. Onsekiz aylık deneyimleri sonucunda öğrenciler, modüllerden çok memnun oldukları ve reçete yazma becerilerinin geliştiği yönünde düşünce bildirmişlerdir (39).

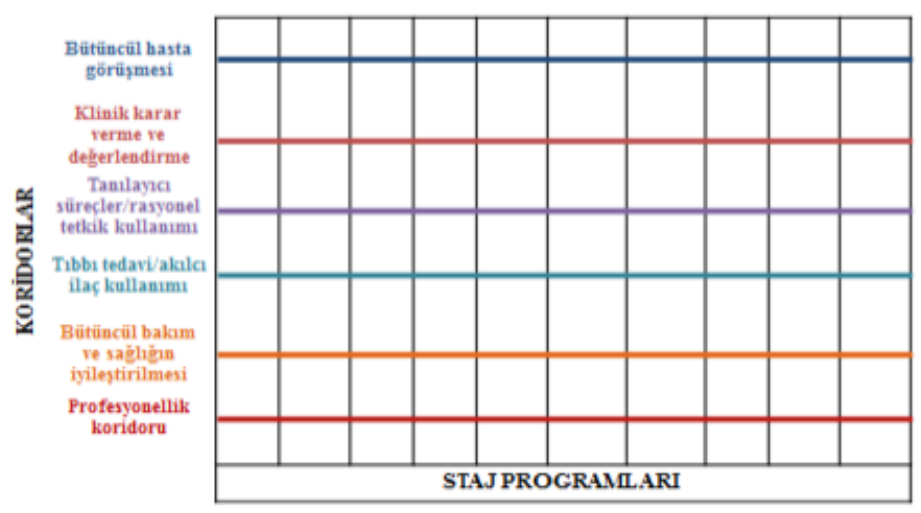

Şekil 1. Tıbbi tedavi ve akılcı ilaç kullanımı eğitimin tüm stajlara entegre edilmesi (Bu şekil yazarın izni alınarak 37 numaralı kaynaktan alınmıştır). 


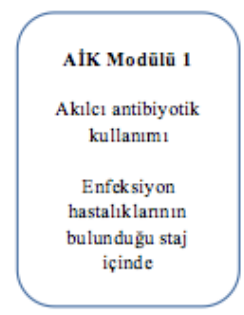

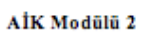

Akıleı ağrı kesici kullanım

Kas-iskelet hastalıklannın yer ald̆ı̆ı staj içinde (Ortopedi, FTR)

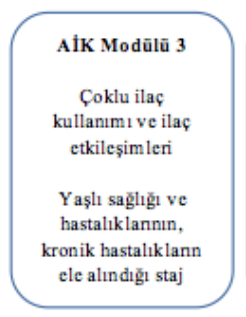

AlK Modūlũ 4

Güvenli hamilelik/emzirme ve ilaç kullanımı

Kadın sağhı̆̆ı, hastalıklan ve doğumun ele alındı̆̆ı staj içinde

Şekil 2. Entegre bir yaklaşımla staj programları içine yerleştirilebilecek Akılcı İlaç Kullanımı Modüllerine örnekler.

Dünya Sağlık Örgütü'nün İyi Reçete Yazma Rehberi doğrultusunda geliştirilecek bu modüllerle öğrencilerin farklı olgular üzerinden uygun ilaçları seçmeleri; etkililik, güvenlilik, uygunluk ve maliyet açısından ilaçları sistematik bir şekilde değerlendirmeleri; reçete yazmaları ve izlem yapmaları mümkün olacaktır. Toplumda sık görülen hastalıklara yönelik (hipertansiyon, diyabet, otitis media, astım, artrit, sinüzit, migren vb) rasyonel farmakoterapi eğitim modüllerinin tıp fakültelerindeki staj programlarına bu şekilde dâhil edilmesi ile öğrencilerin birinci basamakta sıklıkla karşılaşacakları bu hastalıklara yönelik tedaviyi düzenlemede/reçete yazmada kendilerine güven duymalarına, kişisel ilaç formülerlerini hazırlayabilmelerine olanak sağlanacaktır.

Uzun süreli DSÖ-6-basamaklı farmakoloji eğitimi programının etkisini araştırmak amacıyla yapılan bir çalışmada, eğitim programına zengin bağlamsallık katılarak program uygulanmış ve öğrencilerin farmakoloji bilgisi ve farmakoterapi becerileri DSÖ-6-basamaklı entegre program öncesi, sırası ve sonrasında değerlendirilmiştir. Değerlendirme temel farmakoloji soruları $(\mathrm{n}=25)$, klinik farmakoloji soruları $(\mathrm{n}=24)$ sorularak ve farmakoterapi becerisi ( $\mathrm{n}=1$ açık soru) değerlendirilerek yapılmıştır. Entegre bir şekilde tasarlanan bu eğitim programı içinde DSÖ-6-basamaklı farmakoloji ve farmakoterapi eğitimine yer verilmiş, tüm modüllerde farmakoloji ve farmakoterapi prensipleri ile ilaç grupları bütün yönleriyle ele alınmıştır. Dersler büyük gruplarda etkileşimli sınıf dersi ve küçük grup çalışmaları şeklinde yapılmıştır. Örneğin iç hastalıkları stajında öğrenciler için bu modeli kullanarak diyabet ve kalp yetmezliği olan vakalar kullanılmış, ilgili ilaçların farmakodinamik özellikleri öğrenciler tarafindan çalışılarak küçük grup çalışmalarından sunulmuştur (40). Toplam 1652 öğrencinin katıldığ 1 çalışmada öğrencilerin bu entegre program ile temel farmakoloji bilgilerinin ve klinik/uygulamalı farmakoloji bilgilerinin arttığ1, farmakoloji becerilerinin geliştiği belirlenmiş; ayrıca öğrencilerin memnuniyetinin ve günlük pratiklerinde kendilerine olan güveninin arttığı bulunmuştur (40).

Klinik farmakoloji ile temel ve klinik bilimlerin entegre edildiği yatay ve dikey entegrasyonun gerçekleştirildiği eğitim etkinliklerinde öğrenciler diğer disiplinlerle farmakoloji arasındaki etkileşimi anlamakta, ilaçların etki mekanizmasını, yan etkilerini, doz aşımı ve toksisitesini, kontrendikasyonları ve ilaç etkileşimlerini daha iyi kavrayabilmektedirler. Ayrıca öğrenciler çeşitli kaynaklardan bilgi toplama, öğrendiklerini kavrama, temel ve klinik farklı bilgileri entegre etme ve bütünlüklü bir şekilde organize etme, bu bilgileri yeni/farkl1 durumlara/problemlere 
uygulama imkanı bulmaktadırlar. Karşılaştıkları belirsizlikleri, karmaşıkları ve problemleri yönetme becerileri kazanmaktadırlar. Örneğin bu çerçevede uygulanan probleme dayalı öğrenme oturumunda öğrenciler; (i) farmakoloji bilgileri dahil olmak üzere ilgili temel ve klinik bilgileri entegre etme, (ii) hastanın problemini psikolojik, sosyal ve kültürel faktörleri dikkate alarak bütünlüklü bir şekilde değerlendirme, (iii) karıştırıcı faktörleri belirleme; kullanılan ilacın yan etkilerini, ilaç etkileşimlerini, risk faktörlerinin varlığını, genetik, ailesel veya çevresel nedenleri değerlendirme, (iv) hastanın problemleri, hikayesi, önceki araştırmaları, alerjisi, ilaç yan etkileri, almakta olduğu ilaçlar ve sosyal hikayesine ilişkin derinleşme, (v) hastanın semptomlarını, klinik belirtilerini, laboratuvar ve diğer bulgularını değerlendirme ve (vi) tedavi planını oluşturma ve hastayı bilgilendirme gibi bir çok noktada önemli gelişim imkanı yakalayabilmektedirler. Aynı zamanda eleştirel düşünme, kendi kendine öğrenme ve çoklu kaynak kullanımı (textbook, makaleler, multimedya, seminerler vb), toplumun ihtiyaçlarına açık olma, sağlık sistemi ve süreçlerini hastanın ve toplumun faydasını önceleyecek şekilde yetkin bir şekilde yönetme, tıbbi hataları minimuma indirme noktasında yeterlikler kazanabilmektedirler $(40,41,42)$.

Klinik stajların içine entegre edilmiş bu modüllerde oturumların kapsamı ilaçların sadece kullanımları ve etki mekanizmaları ile sınırlı olmamalıdır. Aynı zamanda ilaçların risk değerlendirmelerininyapılması, reçeteyazmadan önce yan etkilerin, kontrendikasyonların, ilaç etkileşimlerinin değerlendirilmesi de yer almalıdır. Yine oturumlar, cümlenin devamında sıralanan bir dizi soruyu içerecek şekilde geliştirilmelidir: ilaçla ilgili hastanın uyarılması gereken durumlar var midir? Riskli bir ilacı reçete yazmadan önce hangi incelemeler yapılmalıdır? Hangi takip parametreleri dikkate alınmalı, takip vizitlerinde hangi sorular sorulmal, ne olursa hasta geri gelmelidir? Takibi gereken ilaç yazıldığında (antibiyotik, warfarin, glukokortikoidler, hipoglisemik ilaçlar) veya başka bir ilaca başlama durumunda hastaya ne tür uyarılar yapılmalıdır? Ve özellikle yaşıı hasta grubunda, çoklu ilaç kullanımı ve ilaç-ilaç etkileşimleri yeterince dikkate alınmış mıdır? (41).

Yukarıda çizilmeye çalışılan çerçeve dikkate alındığında, dünya genelinde yapılan araştırma sonuçları bu çerçevenin uzağında olduğumuza işaret emektedir. Örneğin Avrupa Birliği üyesi 27 ülkeden 185 tıp fakültesindeki ( $\%$ 64) farmakoloji eğitiminin incelendiği bir çalışmaya göre, fakültelerde çoğunlukla geleneksel eğitim yaklaşımları ve yöntemleri uygulanmaktadır. Öğrencilere gerçek ortamda reçete yazma pratiği imkânı sunulmamakta ve öğrenciler mezun olduklarında kendilerini reçete yazma konusunda hazır hissetmemektedirler. Mezuniyet öncesi 5-6 yıllık döneminde, çalışmaya katılan fakültelerin \% $78^{\prime}$ 'inde klinik farmakoloji stajı zorunlu staj, \%12'sinde seçmeli staj olarak yer almakta; \% 10'unda ise staj yapılmamaktadır. Staj programı olan tıp fakültelerinin \% 44'ünde dikey, \% 42'sinde sarmal ve \% 14'ünde yatay entegrasyonun mevcut olduğu; temel farmakoloji eğitimin ilk yıllarında, klinik farmakoloji eğitimin sonraki yıllarda yapıldığı belirlenmiştir (42).

\section{Sonuç}

Akılcı ilaç kullanımı sürecinin en önemli basamağ1 olan ve doktorlar tarafindan gerçekleştirilen "ilaç düzenleme" ve "reçete yazma" basamağı tıp öğrencileri için zor bir işlem olup hataya açık bir süreçtir.

Bundan dolayı AİK ilişkin eğitim etkinlikleri tıp eğitimi programlarının önemli bir bileşenidir. Ancak bu eğitimlerin entegre bir şekilde 6 yıllık tüm eğitim sürecine yedirilmesi; özellikle 
klinik eğitim döneminde, AİK'na ilişkin yeterliklere boylamsal bir koridor olarak, staj programlarının içinde modüller şeklinde yer verilmesi ve son olarak, öğrenme yöntemi olarak olgulara dayalı küçük grupla etkileşimli öğrenme yöntemleri ile işbaşında öğrenme ve değerlendirme yöntemlerinin tercih edilmesi önemlidir. Bunların yapıldığı durumlarda, örneğin öğrenciler DSÖ'nün 6-basamaklı probleme dayalı öğrenme yaklaşımı ile "RASYONEL FARMAKOTERAPI EĞITIMII" almaları durumunda, profesyonel yaşamlarında uzun dönemde bunun etkilerini göreceklerdir. Yine, toplumda sik görülen hastaliklara yönelik (hipertansiyon, diyabet, otitis media, astım, artrit, sinüzit, migren vb) rasyonel farmakoterapi eğitim modüllerinin klinik staj programlarına dâhil edilmesi durumunda ögrenciler, meslek yaşamlarında sık olarak karşılaşacakları hastalıklara ilişkin reçete yazma ve kişisel ilaç formülerlerini hazırlayabilme noktasında kendilerini daha güvenli ve yeterli hissedeceklerdir. Tip eğitimi programlarında yapılacak bu düzenlemeler etkili bir tedavi sağlamanın yanında, hastaların tedaviye uyumunu artırma, ilaç advers etkilerinin azalması, fazla maliyetin önüne geçilmesi ile akılcı ilaç kullanımının yaygınlaştııılması ve devamlılı̆̆ına büyük oranda katk1 sağlayacaktır.

\section{Kaynaklar}

1. World Health Organization The rational use of drugs: Report of the Conference of Experts Nairobi. 1985.

2. World Health Organization "Effective Public Education" in promoting rational drug use. WHO Programme on Essential Drugs and International Network for the Rational Use of Drugs, Nairobi. 1987.
3. Holloway K, van Dijk L. The World Medicines Situation 2011-Rational use of medicines. World Health Organization (WHO), Geneva. WHO/EMP/MIE/2011.2.2.

4. WHO Policy Perspectives on Medicines Promoting Rational Use of Medicines: Core Components No. 005. 2002.

5. Sektörel Bakış - İlaç - 2018. Erişim tarihi ve adresi: 20.05.2019,

https://assets.kpmg/content/dam/kpmg/tr/ pdf/2018/01/sektorel-bakis-2018-ilac.pdf

6. Sektörel Bakış - İlaç - 2019. Erişim tarihi ve adresi: 20.05.2019,

https://assets.kpmg/content/dam/kpmg/tr/ pdf/2019/04/sektorel-bakis-2019-ilac.pdf

7. Türkiye Akılcı İlaç Kullanımı Bülteni Cilt 2; Sayı 9; Eylül 2015 Erişim tarihi ve adresi: 20.05.2019, http://www.akilciilac.gov.tr/wpcontent/uploads/2015/09/aik-bltn-12-i.pdf

8. Akdağ R, Mollahaliloğlu S, Alkan A, Özgülcü Ş, Öncül HG, Akıcı A, Hıfzıssıhha Mektebi Müdürlüğü, Refik Saydam Hıfzıssıhha Merkezi Başkanlığı, Sağlık Bakanlı̆̆ı, Ankara, 2011.

9. Akılcı İlaç Kullanımı (AİK) Ulusal Eylem Planı 2014-2017. Erişim tarihi ve adresi: 20.05.2019, http://www.akilciilac.gov.tr/wpcontent/uploads/2014/11/aik-ulusal-eylemplani.pdf

10. Maxwell SR, Cascorbi I, Orme M, Webb DJ; Joint BPS/EACPT Working Group on Safe Prescribing. Educating European (junior) doctors for safe prescribing. Basic Clin Pharmacol Toxicol 2007;101:395-400.

11. Ross S, Loke YK. Do educational interventions improve prescribing by medical students and junior doctors? A systematic review. Br J Clin Pharmacol 2009;67:662-70. 
12. De Vries TP, Henning RH, Hogerzeil HV, et. Al. Impact of a short course in pharmacotherapy for undergraduate medical students: an international randomised controlled study. Lancet 1995;346:1454-1457.

\section{De Vries TPGM, Henning RH, Hogerzeil} HV, Fresle DA. Guide to Good Prescribing. WHO/Action Programme on Essential Drugs, Geneva, 1994.

14. Parmelee D, Michaelsen LK, Cook S, Hudes PD. Team-based learning: a practical guide: AMEE guide no. 65. Med Teach. 2012;34(5):e275-287.

15. Krupat E, Richards JB, Sullivan AM, Fleenor TJ Jr, Schwartzstein RM. Assessing the Effectiveness of Case-Based Collaborative Learning via Randomized Controlled Trial. Acad Med. 2016;91(5):723-729.

16. Karaalp A, Akici A, Kocabasoglu YE, Oktay S. What do graduates think about a two-week rational pharmacotherapy course in the fifth year of medical education? Med Teach 2003; 25:515-521.

17. Dean B, Schachter M, Vincent C, Barber N. Causes of prescribing errors in hospital inpatients: a prospective study. Lancet 2002;359:1373-1378.

18. Members of EMERGE, Erice Medication Errors Research Group, Agrawal A, Aronson $\mathrm{JK}$, et. Al. Medication errors: problems and recommendations from a consensus meeting. $\mathrm{Br}$ J Clin Pharmacol 2009;67:592-598.

19. McLellan L, Tully MP, Dornan T. How could undergraduate education prepare new graduates to be safer prescribers? .Br J Clin Pharmacol 2012;74:605-613.

20. Aydın B, Gelal A. Akılcı İlaç Kullanımı: Yaygınlaştırılması ve Tıp Eğitiminin Rolü. DEÜ
Tıp Fakültesi Dergisi 2012;26:57-63.

21. Likic R, Maxwell SR. Prevention of medication errors: teaching and training. British Journal of Clinical Pharmacology 2009;67:656661

22. Leape LL, Brennan TA, Laird N, et al. The nature of adverse events in hospitalized patients. Results of the Harvard medical practice study II. N Engl J Med 1991;324:377-384.

23. Barber ND, Dean BS. The incidence of medication errors and ways to reduce them. Clinical Risk 1998;4:103-106.

24. Leape LL, Bates DW, Cullen DJ, et al. Systems analysis of adverse drug events. JAMA 1995;274:35-43.

25. Bates DW, Cullen DJ, Laird N, et al. Incidence of adverse drug events and potential adverse drug events: Implications for prevention. JAMA 1995;274:29-34.

26. Ross S, Maxwell S.Prescribing and the core curriculum for tomorrow's doctors: BPS curriculum in clinical pharmacology and prescribing for medical students. $\mathrm{Br} \mathrm{J}$ Clin Pharmacol. 2012;74(4):644-661.

27. Ellis A. Prescribing rights: are medical students properly prepared for them? Br Med J 2002;324:1591.

28. Heaton A, Webb DJ, Maxwell SR. Undergraduate preparation for prescribing: the views of 2413 UK medical students and recent graduates. Br J Clin Pharmacol. 2008; 66: 128134.

29. Brinkman DJ, Tichelaar J, Graaf S, Otten RHJ, Richir MC, van Agtmael MA. Do finalyear medical students have sufficient prescribing competencies? A systematic literature review. 
Br J Clin Pharmacol. 2018;84(4):615-635.

30. Richir MC, Tichelaar J, Geijteman EC, de Vries TP. Teaching clinical pharmacology and therapeutics with an emphasis on the therapeutic reasoning of undergraduate medical students. Eur J Clin Pharmacol 2008;64:217-24.

31. Khanal S, Buckley $T$, Harnden $C$, et. Al. Effectiveness of a national approach to prescribing education for multiple disciplines. Br J Clin Pharmacol 2013;75:756-762.

32. Akici A, Goren MZ, Aypak C, Terzioglu B, Oktay S. Prescription audit adjunct to rational pharmacotherapy education improves prescribing skills of medical students. Eur J Clin Pharmacol 2005;61:643-650.

33. Akıcı A, Gelal A, Erenmemişoğlu A, Melli M, Babaoğlu M, Oktay Ş. Akılcı ilaç kullanımı eğitimi uygulama sürecinde Türkiye'deki tıp fakültelerinde farmakoloji anabilim dallarının durumunun incelenmesi. Tıp Eğitimi Dünyası 2011;29:11-20.

34. Scobie SD, Lawson M, Cavell G, Taylor K, Jackson SH, Roberts TE. Meeting the challenge of prescribing and administering medicines safely: structured teaching and assessment for final year medical students. Med Educ 2003;37:434-437.

35. Langford NJ, Martin U, Kendall MJ, Ferner RE. Medical errors. Medical schools can teach safe drug prescribing and administration. $\mathrm{Br}$ Med J 2001;322:1424.

36. Vollebregt JA, Metz JC, De Haan M, Richir MC, Hugtenburg JG, De Vries TP. Curriculum development in pharmacotherapy: testing the ability of preclinical medical students to learn therapeutic problem solving in a randomized controlled trial. $\mathrm{Br} \mathrm{J}$ Clin Pharmacol 2006;61:345-351.
37. Gülpınar MA. Klinikte öğrenme ve ölçmedeğerlendirmeye ilişkin genel bir çerçeve. Ulusal Tip Eğitimi Sempozyumu, 10-12 Nisan 2019 Eskişehir, Bildiri Kitapçı̆̆ı, s. 8-19.

38. James H, Tayem YI, Al Khaja KA, Veeramuthu S, Sequeira RP. Prescription Writing in Small Groups as a Clinical Pharmacology Educational Intervention: Perceptions of Preclerkship Medical Students. J Clin Pharmacol. 2016;56(8):1028-1034.

39. Zgheib NK, Simaan JA, Sabra R. Using teambased learning to teach clinical pharmacology in medical school: student satisfaction and improved performance. J Clin Pharmacol. 2011;51(7):1101-1111.

40. Keijsers CJ, Segers WS, de Wildt DJ, Brouwers JR, Keijsers L, Jansen PA. Implementation of the WHO-6-step method in the medical curriculum to improve pharmacology knowledge and pharmacotherapy skills. Br J Clin Pharmacol 2015;79(6):896-906.

41. Azer SA, Frauman AG. Seeing the wood for the trees: approaches to teaching and assessing clinical pharmacology and therapeutics in a problem-based learning course. Ann Acad Med Singapore. 2008;37(3):204-209.

42. Brinkman DJ, Tichelaar J, Okorie M et.al. ; Education Working Group of the European Association for Clinical Pharmacology and Therapeutics (EACPT). Pharmacology and Therapeutics Education in the European Union Needs Harmonization and Modernization: A Cross-sectional Survey Among 185 Medical Schools in 27 Countries. Clin Pharmacol Ther. 2017;102(5):815-822. 